\title{
Effects of Intrauterine and Early Postnatal Growth Restriction on Hypothalamic Somatostatin Gene Expression in the Rat
}

\author{
CARLA T. HUIZINGA, CEES B.M. OUDEJANS, ROBERT A. STEINER, \\ DONALD K. CLIFTON, AND HENRIETTE A. DELEMARRE-VAN DE WAAL \\ Research Institute for Endocrinology, Reproduction and Metabolism, Departments of Pediatrics [C.T.H., \\ H.A.D.] and Clinical Chemistry [C.B.M.O.], University Hospital "Vrije Universiteit," 1007 MB \\ Amsterdam, The Netherlands; and Departments of Obstetrics and Gynecology [D.K.C., R.A.S.] and \\ Physiology and Biophysics [R.A.S.], University of Washington, Seattle, Washington 98195, U.S.A.
}

\begin{abstract}
In the human, intrauterine growth retardation (IUGR) can result in persistent postnatal growth failure, which may be attributable, in part, to abnormal GH secretion. Whether putative alterations in GH secretion are the result of abnormalities intrinsic to the pituitary or reflect changes in the production of $\mathrm{GH}-$ releasing hormone or somatostatin (SS) is unknown. We tested the hypothesis that growth failure associated with IUGR or early postnatal food restriction (FR) is caused by a central defect in hypothalamic SS gene expression. Both models displayed persistent growth failure postnatally without any catch-up growth. We measured levels of SS mRNA levels in rats experimentally subjected to IUGR or FR. SS mRNA levels were measured by semiquantitative in situ hybridization throughout development. Levels of SS mRNA in the periventricular nucleus were significantly higher in both male and female IUGR rats in the juvenile and adult stages compared with matched controls ( $p$ $\leq 0.05$ ). FR was associated with higher SS mRNA levels only in neonatal female rats $(p \leq 0.05)$. These results suggest that
\end{abstract}

\section{ABSTRACT}

intrauterine malnutrition induces a persistent increase in the expression of SS mRNA in the periventricular nucleus, whereas early postnatal FR results in only a transient increase in SS gene expression. Because IGF-I levels were normal in juvenile IUGR and FR rats, central dysregulation of SS neurons does not appear to be the cause of early postnatal growth failure in either model. However, these observations are consistent with the hypothesis that nutritional stress at critical times during development can have persistent and potentially irreversible effects on organ function. (Pediatr Res 48: 815-820, 2000)

FR, food restriction

\section{Abbreviations}

GHRH, GH, releasing hormone

IUGR, intrauterine growth retardation

NPY, neuropeptide Y

PeN, periventricular nucleus

SS, somatostatin
The fetus is dependent on the transfer of oxygen and nutrients across the placenta. The impairment of uteroplacental blood flow or placental function may interfere with the delivery of nutrients to the fetus. This can lead to IUGR and a disruption of normal fetal development, resulting in low birth weight (1-3). Furthermore, low birth weight increases the risk of adult-onset disorders such as non-insulin-dependent diabetes mellitus, hypertension, and cardiovascular diseases $(4,5)$. These observations suggest that inadequate fetal nutrition can permanently alter the development of organ systems, resulting in their dysfunction in adult life (4).

Received November 11, 1999; accepted July 12, 2000.

Correspondence and reprint requests: Henriette A. Delemarre-van de Waal, University Hospital "Vrije Universiteit," Department of Pediatrics, Box 7057, 1007 MB Amsterdam, The Netherlands.

Supported by Ferring, The Netherlands.
Many children experiencing IUGR show catch-up growth within the first 2 y of life, but a significant fraction (15 to 40\%) fail to do so (6). In animals with experimentally induced IUGR, the limited supply of substrates results in an irreversible slowing of the fetal growth rate in late gestation, which persists even after the substrate limitation is removed (7). The lack of catch-up growth in animals with IUGR makes them an attractive model for studying the mechanisms responsible for growth retardation in low birth weight humans who never attain normal adult stature.

Postnatal growth is regulated primarily by GH acting through IGF-I. The secretion of GH by the pituitary is controlled by the reciprocal and coordinated discharge of SS and GHRH from hypothalamic neurons located in the PeN and arcuate nucleus, respectively (8). The extent to which the central mechanisms governing the activity of the GH axis are involved in mediating postnatal growth failure as a conse- 
quence of either prenatal or early postnatal malnutrition is unknown; however, approximately half the children who are born small for gestational age and continue to undergo growth retardation appear to have abnormal GH secretory patterns (9). We postulated that nutrient restriction during the perinatal period causes permanent alterations in the function of hypothalamic SS neurons, contributing to abnormal growth and development later in life. To test this hypothesis, we assessed the effects of perinatal nutrient restriction on cellular levels of SS mRNA in the PeN of rats at different stages of development (neonatal, juvenile, and adult). To compare the effects of prenatal versus postnatal malnutrition on long-lasting changes in postnatal development, we used two types of nutrient restriction-experimentally induced IUGR and postnatal FR. We report that, in contrast to postnatal FR, prenatal malnutrition induces a persistent elevated expression of SS mRNA levels in the PeN, indicating that nutritional stress during fetal development may have persistent and potentially irreversible effects on the GH axis.

\section{MATERIALS AND METHODS}

Animals and surgical procedures. Timed-pregnant Wistar rats were obtained from Harlan CPB (Rijswijk, The Netherlands) and housed under a constant light-dark cycle (lights on, $0600 \mathrm{~h}$; lights off, $1800 \mathrm{~h}$ ) in a temperature-controlled room $\left(22 \pm 1^{\circ} \mathrm{C}\right)$.

For experimental induction of IUGR, the method of Wigglesworth (1) was used. Pregnant females (d 17) were anesthetized with a mixture of Aescoket, Aesculaap BU, Boxtel, The Netherlands $(100 \mathrm{mg} / \mathrm{mL})$ and Xylazine, Bayer Ag, Leverkusen, Germany $(20 \mathrm{mg} / \mathrm{mL}$ ) (diluted 4:1, $1 \mathrm{~mL} / \mathrm{kg}$ body weight, intramuscularly). The mesometrium of one uterine horn was exposed through a midline incision in the abdominal wall, and the uterine artery was ligated near the cervical end of the arterial arcade. The uterine artery of the other horn was ligated in a similar manner, and the abdomen was closed. After surgery, females were allowed to give birth. Pups were considered growth retarded if their weights at postnatal $\mathrm{d} 2$ were at least 2 SD less than that of control pups born from nonoperated mothers. The litter sizes of both IUGR and control animals were restricted to six pups per mother. Postnatal growth retardation was induced by FR during the neonatal period by increasing the litter size to 20 pups per mother (male/female ratio 1:1) from postnatal d 1 onward (10).

For each experimental group, the mother had free access to rat chow and tap water. The pups remained with their mother until sacrifice or until weaning at day 25 . After weaning, the rats were housed in groups of two to three animals per cage with free access to food and tap water. All procedures were approved by the Institutional Animal Ethics Committee.

Experimental design. Levels of SS mRNA in the PeN were measured in IUGR, FR, and control rats at different developmental stages: $10 \mathrm{~d}$ (neonatal), 24-28 d (juvenile), and 72-74 $\mathrm{d}$ (adulthood). Male and female rats were used, and each group consisted of six animals-except for the female 25-d-old IUGR group and the female 75-d-old control group, which contained four and five animals, respectively. Body weight was used to assess growth, as in the rat, weight gain is a good indicator of growth and correlates well with other linear growth measures (11).

Tissue preparation. Rats were killed between $0900 \mathrm{~h}$ and $1100 \mathrm{~h}$. The brains were rapidly removed and frozen in 2-methylbutane cooled with dry ice, and trunk blood was collected. Brains and serum were stored at $-80^{\circ} \mathrm{C}$ until further processing. Coronal cryostat sections were cut at $20 \mu \mathrm{m}$ and thawmounted on 2\% 3-aminopropylethoxysilane-coated slides. Consecutive brain sections were cut starting rostrally at the $\mathrm{PeN}(-0.26)$ and continuing caudally to the end of the arcuate nucleus (-3.60) (12) Four sets of slides were collected; every fourth slide was placed into a given set. Slides were stored at $-80^{\circ} \mathrm{C}$ until in situ hybridization was performed. One set (5-8 sections per animal) was used for in situ hybridization.

IGF-I serum levels. IGF-I serum levels $(\mathrm{ng} / \mathrm{mL})$ were measured after acid-ethanol extraction of its binding proteins, using an RIA from Medgenix (Biosource Diagnostics, Fleurus, Belgium). The intra-assay coefficient of variability for the IGF-I assay was $7 \%$ (for values $<100 \mathrm{ng} / \mathrm{mL}$ ) and $5 \%$ (for values $>100 \mathrm{ng} / \mathrm{mL}$ ). The interassay coefficient of variability was $10 \%$.

Preparation of ${ }^{35}$ S-labeled SS cRNA probes. Riboprobes complementary to the coding region of preproSS mRNA were generated by in vitro transcription of the 395-bp cDNA fragment of rat preproSS cloned into pSP65 vector (13). Antisense cRNA probes were made by linearizing this plasmid by HindIII and transcribing with SP6 RNA polymerase in the presence of $35 \%\left[{ }^{35}\right.$ S]UTP (DuPont, Belgium). Transcription was terminated by addition of RQ1 DNase. The cRNA probe was precipitated with $1 / 10$ vol of $3 \mathrm{M}$ sodium acetate, $\mathrm{pH}$ 5.2, and 2.5 vol of ethanol at $-20^{\circ} \mathrm{C}$. Labeled precipitated riboprobes were resuspended in $100 \mathrm{mM}$ DTT.

In situ hybridization. Six in situ hybridization assays were performed. The tissues from female animals for each developmental stage were run in three separate assays, and the tissues from male animals for each developmental group were run in the other three. Sections were air-dried at room temperature and fixed for $20 \mathrm{~min}$ in freshly prepared $4 \%$ paraformaldehyde in $0.1 \mathrm{M}$ PBS ( $\mathrm{pH} 7.4$ ), rinsed three times for $5 \mathrm{~min}$ in PBS, and rinsed briefly in water. After acetylation for $10 \mathrm{~min}$ with $0.25 \%$ acetic anhydride in $1 \%$ triethanolamine and two washing steps in PBS, sections were rinsed in $2 \times$ standard saline citrate (SSC) for at least $5 \mathrm{~min}$. The slides were prehybridized for $2 \mathrm{~h}$ at $37^{\circ} \mathrm{C}$ in hybridization buffer containing $50 \%$ formamide, $10 \%$ dextran sulfate, $1 \mathrm{x}$ Denhardt's solution, $0.2 \times$ SSC, $500 \mu \mathrm{g} / \mathrm{mL}$ denatured salmon sperm DNA, and 250 $\mu \mathrm{g} / \mathrm{mL}$ tRNA (Roche Molecular Biochemicals, Indianapolis, IN, U.S.A.). After prehybridization, the denatured SS cRNA probe, in hybridization buffer at a concentration of $2 \times 10^{6}$ $\mathrm{dpm} / 50 \mu \mathrm{L}$, was applied to the tissue. Slides were covered with Parafilm, and the sections were incubated overnight in moist chambers at $50^{\circ} \mathrm{C}$. The following day, the sections were rinsed in $1 \times \mathrm{SSC}$ and washed twice under high stringency in $0.1 \times$ SSC at $60^{\circ} \mathrm{C}$, followed by treatment with $30 \mu \mathrm{g} / \mathrm{mL}$ RNase A in RNase buffer (10 mM Tris, pH 8.0; 1 mM EDTA; $50 \mathrm{mM}$ $\mathrm{NaCl})$ at $37^{\circ} \mathrm{C}$ for $30 \mathrm{~min}$. Finally, the sections were washed twice in $0.1 \times \mathrm{SSC}$ at room temperature and air-dried. 
Control experiments. Control experiments were performed as previously reported to demonstrate the specificity of the binding of the preproSS cRNA probe, as well as to determine the optimal probe concentration (13).

Autoradiography and image analysis. Hybridized slides were dipped in emulsion (Ilford K5, Ilford, Imaging KK Ltd, Mobberley, Cheshire, U.K.) that had been diluted 1:1 in 2\% glycerol solution and heated to $45^{\circ} \mathrm{C}$ in a water bath. The slides were allowed to air-dry for $1 \mathrm{~h}$, placed in light-tight boxes, exposed for $5 \mathrm{~d}$ at $4^{\circ} \mathrm{C}$, developed, counterstained with nuclear fast red, and dehydrated through a series of alcohol followed by application of coverslips.

Age- and sex-matched slides were assigned a random threeletter code, alphabetized, and read in random order with an automated image-processing system by an operator unaware of the animal's experimental group. This system consisted of a PixelGrabber Video acquisition board (Perceptics, Knoxville, TN, U.S.A.) attached to a Macintosh fx computer (Apple Computer, Cupertino, CA, U.S.A.). Video images were obtained by a Dage model 65 camera (Dage, Inc., Michigan City, IN, U.S.A.) attached to a Zeiss Axioskop (Zeiss, New York, NY, U.S.A.) equipped with a $\times 40$ objective and side-illumination.

In each section, the number of grains over each individual cell in the PeN was determined by use of the UW Grain Counting Analysis Program (D. Clifton, Seattle WA, U.S.A.). The total number of labeled cells in the PeN (bregma -0.26 until -1.80) (12) on both sides of the third ventricle was counted. To verify the specificity of the changes in the PeN, the number of grains in SS mRNA-expressing neurons in the cortex of adult rats was also analyzed. From each animal, a total of 100 cortical cells, divided over five to eight slides, were analyzed at the level of bregma $-0.26 \mathrm{~mm}$ to $-1.80 \mathrm{~mm}$ (14). Cells were considered labeled when the number of silver grains overlying the cytoplasm were greater than 10 times the background levels. The number of grains per cell is referred to as the mRNA signal, which is a semiquantitative estimate of intracellular mRNA levels that allows the comparison of relative differences in mRNA expression levels among experimental groups.

Statistical analysis. The mean grains per cell of each individual animal was used to determine the overall mean and SEM of each experimental group. The effects of IUGR and FR on SS mRNA expression, IGF-I serum levels, and weight were assessed by a one-way ANOVA followed by Fisher's protected least significant difference test. Differences were considered statistically significant when $p \leq 0.05$.

\section{RESULTS}

Both IUGR and FR caused persistent growth failure throughout postnatal development in both groups, as indicated by lower body weights (Fig. 1).

Levels of SS mRNA signal levels were significantly increased in juvenile IUGR females $(p<0.050)$ and males $(p<0.010)$ to 120 and $135 \%$ of control, respectively (Figs. 2, $B$ and $E$, and 3, $F$ and $G$ ). This elevation in SS mRNA signal was sustained over development and into adulthood: adult female and male IUGR rats showed a $155 \%$ increase and $130 \%$ increase, respectively, compared with controls ( $p$ $<0.002$; Fig. 2, $C$ and $F$ ). Levels of SS mRNA in neonatal IUGR and control animals were not significantly different in

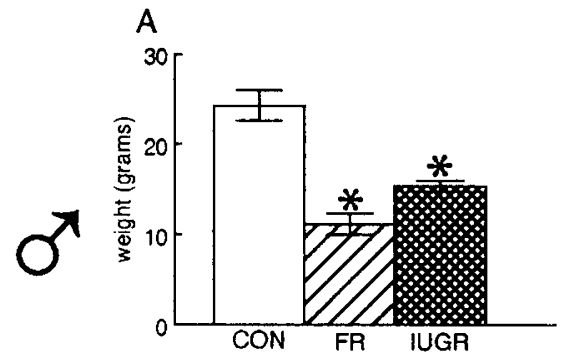

NEONATAL

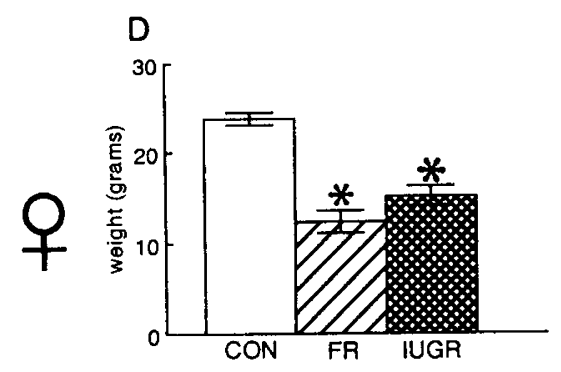

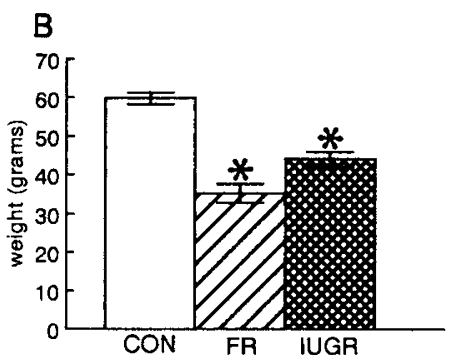

JUVENILE

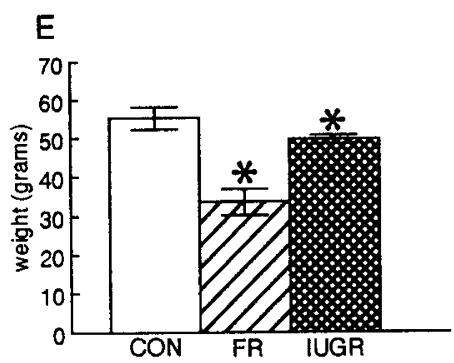

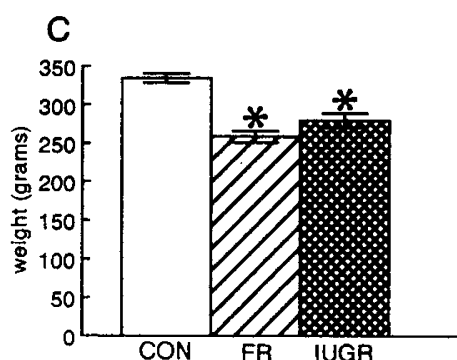

ADULT

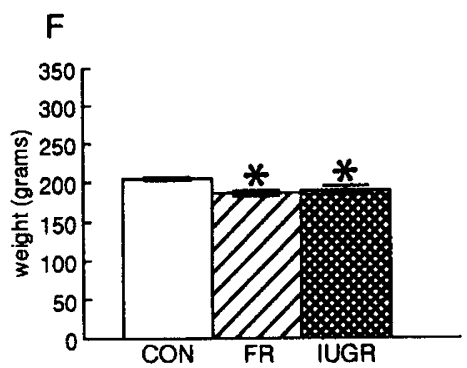

Figure 1. Weight of male and female neonatal $(A, D)$, juvenile $(B, E)$, and adult $(C, F)$ IUGR, FR, and control $(C O N)$ rats. The results are expressed as the mean \pm SEM for each experimental group; *significantly different compared with CON $(p<0.05)$. 


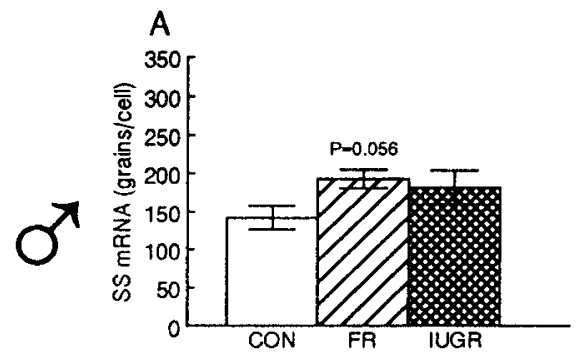

NEONATAL

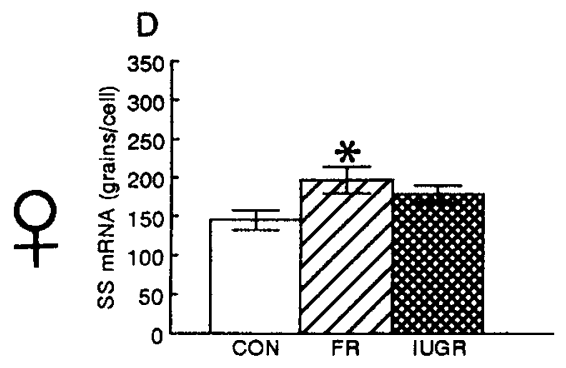

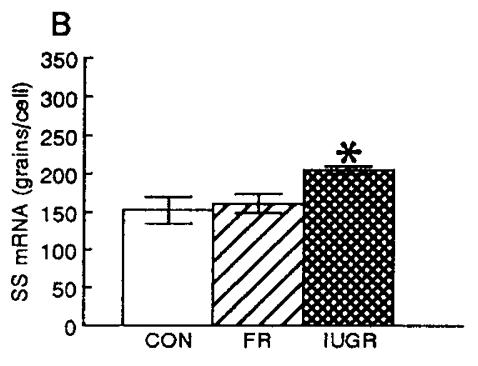

JUVENILE

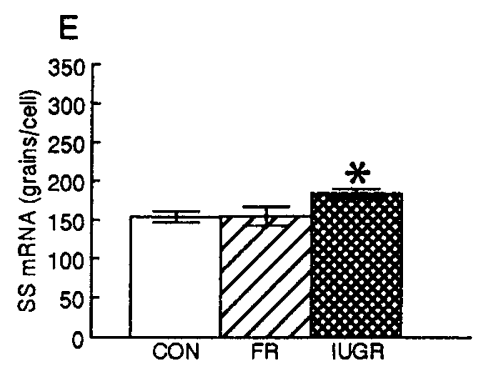

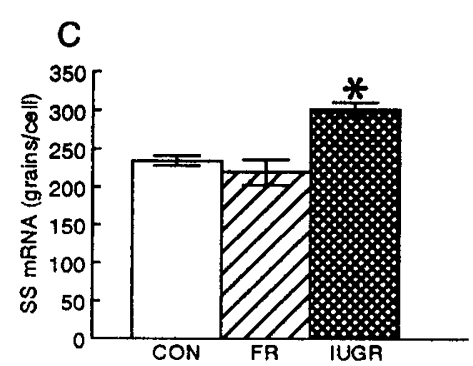

ADULT

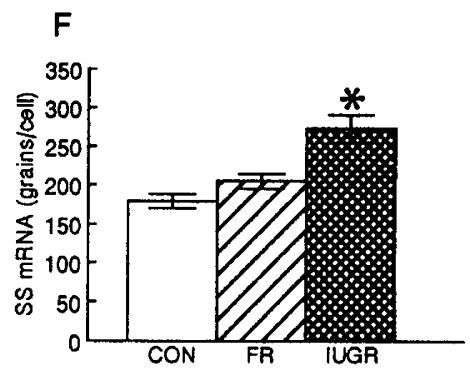

Figure 2. SS mRNA signal levels in the PeN of the hypothalamus of male and female neonatal $(A, D)$, juvenile $(B, E)$, and adult $(C, F)$ IUGR, FR, and control $(C O N)$ rats. Values are given as mean \pm SEM; *significantly different compared with $\operatorname{CON}(p<0.05)$.

either sex ( $p=0.112$ for females, $p=0.122$ for males; Fig. 2, $A$ and $D)$.

In female neonatal FR animals, the SS mRNA signal was $135 \%$ higher than in control animals of a similar age and sex $(p<0.020)$. In the male neonatal FR rat, SS mRNA signal levels were $135 \%$ higher compared with controls, although this apparent difference was not statistically significant ( $p=0.056$; Fig. 2, $A$ and $D$ ). Levels of SS mRNA in FR animals of juvenile and adult ages were not significantly different from controls (Figs. 2, $B-F$, and 3, $D$ and $E$ ).

SS mRNA levels in the cortex of both sexes were not significantly affected by IUGR or FR at the adult stage (Table 1). These results suggest that perinatal malnutrition affects only a subset of the SS gene-expressing neurons in the CNS, including those neurons that participate in the regulation of $\mathrm{GH}$ secretion.

Serum levels of IGF-I increased throughout development in both males and females, in the controls as well as in the two growth-retarded models (Table 2). IGF-I levels were not significantly altered in the neonatal FR and IUGR rats, compared with their sex- and age-matched controls. The levels at the juvenile stage were significantly lower in the FR male $(p<0.025)$ and female $(p<0.05)$ rats and in the IUGR male rat $(p<0.05)$. The IGF-I levels in the adult FR and IUGR rats were not significantly different from controls (Table 2).

\section{DISCUSSION}

Postnatal growth is governed by neuroendocrine mechanisms that regulate the coordinated discharge of SS and GHRH from neurons in the hypothalamus, which in turn regulates GH secretion and other downstream targets, including IGF-I secretion $(3,14)$. In this study, perinatal restriction of nutrients resulted in growth failure, which persisted into adulthood, without signs of catch-up growth. This observation confirms previous reports in the rat $(7,15,16)$ but contrasts with the human condition in which the majority of children born small for gestational age show catch-up growth within the first $2 \mathrm{y}$ of life (6). There was a striking similarity in the way that exper-

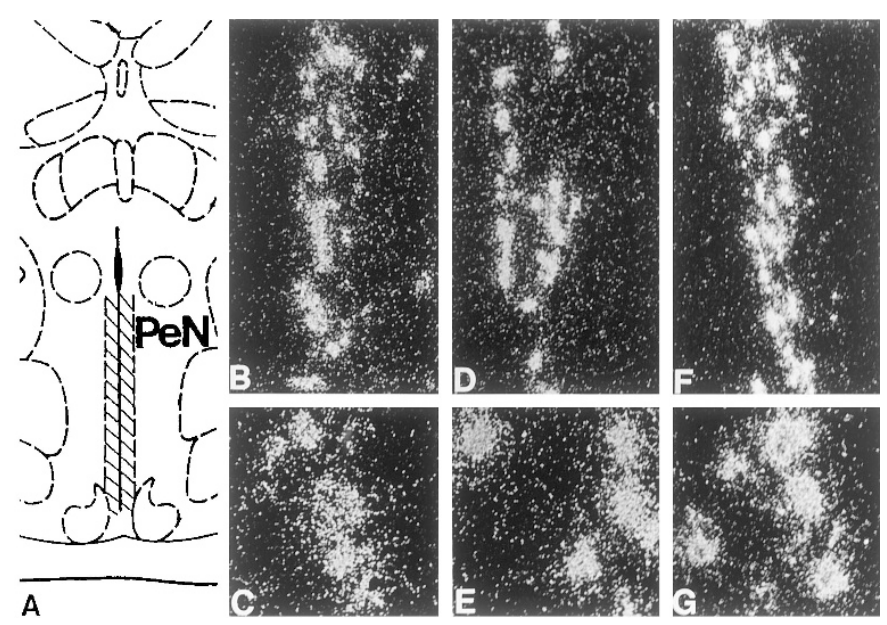

Figure 3. Photomicrographs of neurons in the PeN under darkfield illumination after in situ hybridization for SS. Silver grains from the radiolabeled SS probe appear as white dots. Clusters of silver grains mark cells containing SS mRNA. $A$, schematic overview of the PeN [bregma -1.40 according to Paxinos and Watson (12)]. $B-G$, SS mRNA silver grain distributions in the PeN of a male juvenile control rat $(B, C)$, a male juvenile FR rat $(D, E)$, and a male juvenile IUGR rat $(F, G)$. Magnification was $\times 10$ in $B, D, F$ and $\times 25$ in $C, E, G$. 
Table 1. SS mRNA levels of neurons in the cortex and PeN of adult male and female IUGR, FR, and control (CON) rats

\begin{tabular}{|c|c|c|c|c|c|c|}
\hline \multirow[b]{2}{*}{ Site } & \multicolumn{3}{|c|}{ Male } & \multicolumn{3}{|c|}{ Female } \\
\hline & $\mathrm{CON}$ & FR & IUGR & $\mathrm{CON}$ & FR & IUGR \\
\hline $\mathrm{PeN}$ & $236 \pm 7$ & $220 \pm 17$ & $302 \pm 10^{*}$ & $179 \pm 8$ & $205 \pm 10$ & $273 \pm 18^{*}$ \\
\hline
\end{tabular}

The results are expressed as the mean \pm SEM for each experimental group.

* Significantly different compared with controls $(p<0.05)$.

Table 2. Serum levels of IGF-I (ng/mL) over development in male and female IUGR, FR, and control (CON) rats

\begin{tabular}{lllcllrr}
\hline & \multicolumn{3}{c}{ Males } & & \multicolumn{3}{c}{ Females } \\
\cline { 2 - 3 } Group & Neonatal & Juvenile & Adult & & Neonatal & Juvenile \\
\hline CON & $129 \pm 8$ & $368 \pm 22$ & $1216 \pm 65$ & & $122 \pm 11$ & $372 \pm 30$ & $1016 \pm 71$ \\
FR & $107 \pm 7$ & $243 \pm 47^{*}$ & $1044 \pm 62$ & & $102 \pm 14$ & $234 \pm 56^{*}$ & $961 \pm 33$ \\
IUGR & $113 \pm 13$ & $250 \pm 32^{*}$ & $1162 \pm 43$ & & $109 \pm 11$ & $449 \pm 47.2$ & $1162 \pm 45$ \\
\hline
\end{tabular}

The results are expressed as the mean \pm SEM for each experimental group.

* Significantly different compared with controls $(p<0.05)$.

imentally induced IUGR and early postnatal FR affected postnatal growth. However, differences in the pattern of SS mRNA expression over development in IUGR and FR rats suggest that different pathways are responsible for the reduced rates of growth in these two models.

In this study, hypothalamic levels of SS mRNA were elevated in juveniles and adult animals that underwent experimental IUGR, whereas a different pattern of SS mRNA expression was observed in FR rats - both male and female FR animals exhibited only transiently increased levels of SS mRNA during the neonatal period (when FR was occurring), followed by normalization of SS expression (relative to controls) at later stages of development. The transient neonatal increase in SS mRNA expression in FR rats may be explained as a short-term response to the decreased food intake and its associated stress (17). During FR, a decrease in circulating levels of leptin (and possibly insulin) leads to the activation of hypothalamic NPY neurons (18). Because NPY is thought to induce SS secretion, an increase in NPY activity could mediate the increase in SS gene expression that we report here $(19,20)$.

In IUGR rats, we observed an increase in SS mRNA levels that did not become apparent until the juvenile stage and persisted into adulthood-long after the abatement of nutrient restriction. These results are consistent with a proposal by Barker et al. (4) that fetal malnutrition causes persistent endocrine changes leading to abnormal structure, function, and disease in adult life. Indeed, epidemiologic evidence suggests that a low birth weight increases the risk of developing a number of adult-onset disorders, including non-insulindependent diabetes mellitus, hypertension, and cardiovascular diseases $(4,5)$. Furthermore, animal studies have shown that malnutrition and reduced oxygen flow during pregnancy, which impairs growth during a critical developmental period, may permanently compromise the development and physiology of a variety of organ systems, even when the deleterious circumstances have been ameliorated after birth $(3,21)$. Widdowson and McCance $(10,22)$ showed that rapid cell division is the hallmark of these critical periods of fetal and early postnatal growth. Consequently, the major adaptive strategy of the fetus or neonate to the lack of nutrients and oxygen is to reduce its rate of cell division (5). This process occurs as a direct result of undernutrition, as well as indirectly via an altered bioavailability of growth factors and other growthrelated substances. Thus, malnutrition during pregnancy may have a long-lasting effect on the central mechanisms governing the GH axis, an effect that becomes evident in the juvenile period and persists into adulthood as an insidious reminder of the insult that occurred during a brief, albeit critical, window of developmental change in utero.

Because fetal growth is primarily regulated by insulin and IGF-I (14), it is likely that growth retardation in IUGR fetuses is mediated by the disruption of one or both of these factors. From SS mRNA measurements, it is tempting to speculate that during the postnatal phase, when growth is under the control of the GH axis, growth retardation in IUGR rats is caused by increased activity of the hypothalamic SS neurons that regulate GH secretion. However, despite the fact that IUGR rats exhibited postnatal growth failure, their serum levels of IGF-I increased throughout development and in adults were indistinguishable from control values. These observations suggest that GH secretion was normal in IUGR rats, not withstanding the alteration in SS neurons that was caused by prenatal malnutrition. This conclusion is also supported by our earlier observation that IUGR animals display normal GH levels (23). Therefore, it appears that within the GH axis of IUGR rats, compensatory mechanisms counteract increased SS activity to maintain normal IGF-I secretion. One of the most likely candidates for effecting this compensation is the diametric partner of SS, GHRH. Whether increased GHRH activity (which would stimulate GH and consequently IGF-I secretion) accompanies IUGR remains to be determined.

If serum IGF-I levels (and by inference GH levels) are normal in adult rats that experienced perinatal FR, why do these animals display persistent growth retardation? One plausible explanation, at least for IUGR rats, is that because these animals are small at birth, they require higher than normal GH levels to stimulate catch-up growth, but they are prevented from attaining high $\mathrm{GH}$ secretion rates owing to increased SS activity. An alternative explanation that would apply to both models of perinatal growth restriction is that this treatment 
reduces the efficacy of IGF-I. For example, perinatal malnutrition could increase the production of IGF-I inhibiting factors (e.g. binding proteins) or decrease the expression of IGF-I receptors. Similar reasoning has been used to explain corticoidrelated growth failure (24). Finally, it is possible that at least part of the growth retardation in these experimental models is the result of factors that are unrelated to the $\mathrm{GH}$ axis. For example, the thyroid axis also plays an important role in postnatal growth (25). Because TSH secretion is inhibited by SS $(26,27)$, it is possible that increased SS expression after IUGR causes a suppression of the thyroid axis that results in a reduced rate of growth. Clearly, additional studies will be required to ferret out the multifactorial etiology of sustained growth retardation that follows perinatal malnutrition.

In summary, we have shown that rats that experience either experimentally induced IUGR or early postnatal FR show growth retardation that extends into adulthood. After intrauterine malnutrition, juvenile and adult rats have significantly increased levels of SS mRNA in the hypothalamic PeN. In contrast to intrauterine malnutrition, early postnatal FR also increases the expression of SS mRNA, but only during the period of FR. In both models of growth retardation, IGF-I levels were not affected by the treatment. These observations suggest that nutritional stress during a critical developmental window produces a persistent and potentially irreversible alteration in the activity of the hypothalamic-pituitary axis.

Acknowledgment. We gratefully acknowledge Dr. C. PoppSnijders and her staff for measurement of the IGF-I.

\section{REFERENCES}

1. Wigglesworth JS 1964 Experimental growth retardation in the foetal rat. J Pathol Bacteriol 88:1-13

2. Barker DJP 1996 Growth in utero and coronary heart disease. Nutr Rev 54:S1-S7

3. Gluckman PD, Harding JE 1997 The physiology and pathophysiology of intrauterine growth retardation. Horm Res 48(suppl 1):11-16

4. Barker DJP, Gluckman PD, Godfrey KM, Harding JE, Owens JA, Robinson JS 1993 Fetal nutrition and cardiovascular disease in adult life. Lancet 341:938-941

5. Barker DJP, Hales CN, Fall CHD, Phipps K, Clarck PMS 1993 Type 2 (non-insulindependent) diabetes mellitus, hypertension and hyperlipidaemia (syndrome X): relation to reduced fetal growth. Diabetologia 36:62-67
6. Boersma B, Wit JM 1997 Catch-up growth. Endocr Rev 18:646-661

7. Woodall SM, Breier BH, Johnston BM, Gluckman PD 1996 A model of intrauterine growth retardation caused by chronic maternal undernutrition in the rat: effects on the somatotrophic axis and postnatal growth. J Endocrinol 150:231-242

8. Tannenbaum GS 1991 Neuroendocrine control of growth hormone secretion. Acta Paediatr Suppl 372:5-16

9. Ackland FM, Stanhope R, Eyre C, Hamill G, Jones J, Preece MA 1988 Physiological growth hormone secretion in children with short stature and intra-uterine growth retardation. Horm Res 30:241-245

10. Widdowson EM, McCance RA 1963 The effect of finite periods of undernutrition at different ages on the composition and subsequent development of the rat. Proc R Soc Lond 185:329-342

11. Hughes P, Tanner J 1970 A longitudinal study of the growth of the blackhooded rat: methods of measurement and rates for growth for skull, limbs pelvis, nose-rump and tail lengths. J Anat 106: 349-370

12. Paxinos G, Watson C 1986 The Rat Brain in Stereotaxic Coordinates, 2nd Ed Academic Press, London

13. Rogers KV, Vician L, Steiner RA, Clifton DK 1987 Reduced preprosomatostatin messenger ribonucleic acid in the periventricular nucleus of hypophysectomized rats determined by quantitative in situ hybridization. Endocrinology 121:90-93

14. Gluckman PD, Cutfield W, Harding JE, Milner D, Jensen E, Woodall SM, Gallaher BH, Bauer MK, Breier BH 1996 Metabolic consequences of intrauterine growth retardation. Acta Paediatr Suppl 417:3-6

15. Sadiq HF, Das UG, Tracy TF, Devaskar SU 1999 Intrauterine growth restriction differentially regulates perinatal brain and skeletal muscle glucose transporters. Brain Res 823:96-103

16. Rajakumar PA, He J, Simmons RA, Devaskar SU 1998 Effect of uteroplacental insufficiency upon brain neuropeptide $\mathrm{Y}$ and corticotropin-releasing factor gene expression and concentrations. Pediatr Res 44:168-174

17. Thissen JP, Ketelslegers JM, Underwood LE 1994 Nutritional regulation of the insulin-like growth factors. Endocr Rev 15:80-101

18. Plagemann A, Harder T, Rake A, Waas T, Melchior K, Ziska T, Rohde W, Dorner G 1999 Observations on the orexigenic hypothalamic neuropeptide Y-system in neonatally overfed weanling rats. J Neuroendocrinol 11:541-546

19. Chan YY, Clifton DK, Steiner RA 1996 Role of NPY neurones in GH-dependent feedback signalling to the brain. Horm Res 45(suppl 1):12-14

20. Rettori V, Milenkovic L, Aguila MC, McCann SM 1990 Physiologically significant effect of neuropeptide Y to suppress growth hormone release by stimulating somatostatin discharge. Endocrinology 126:2296-2301

21. Lucas A 1994 Role of nutritional programming in determining adult morbidity. Arch Dis Child 71:288-290

22. Widdowson EM, McCance RA 1974 The determinants of growth and form. Proc R Soc Lond 185:1-17

23. Engelbregt MJT, Houdijk ECAM, Popp-Snijders C, Delemarre-van de Waal HA 1997 Persistent growth impairment despite normal growth hormone secretion and normal serum IGF-I levels in male and female intra-uterine growth retarded rats. Horm Res 48:Abstr 277

24. Edén S 1979 Age- and sex-related differences in episodic growth hormone secretion in the rat. Endocrinology 105:555-560

25. Tonshof B, Mehls O 1996 Interaction between glucocorticoids and the somatotrophic axis. Acta Paediatr Suppl 417:72-75

26. Ramos S, Goya L, Alvarez C, Pascual-Leone AM 1998 Mechanism of hypothyroidism action on insulin-like growth factor-I and -II from neonatal to adult rats: insulin mediates thyroid hormone effects in the neonatal period. Endocrinology 139:47824792

27. Patel YC, Srikant CB 1986 Somatostatin mediation of adenohypophysial secretion. Annu Rev Physiol 48:551-567 